\title{
Commentary: What in the world is glial fibrillary acidic protein?
}

\author{
Charles B. Huddleston, MD, and Andrew C. Fiore, MD
}

\author{
From the Division of Cardiothoracic Surgery, St Louis University School of Medicine, St Louis, Mo. \\ Disclosures: Authors have nothing to disclose with regard to commercial support. \\ Received for publication March 12, 2019; revisions received March 12, 2019; accepted for publication March 12, \\ 2019; available ahead of print April 25, 2019. \\ Address for reprints: Charles B. Huddleston, MD, 1465 S. Grand Blvd, 5th Floor, Glennon Hall, St Louis, MO \\ 63104 (E-mail: Charles.huddleston@health.slu.edu). \\ J Thorac Cardiovasc Surg 2019;158:e175-6 \\ $0022-5223 / \$ 36.00$ \\ Copyright (C) 2019 by The American Association for Thoracic Surgery \\ https://doi.org/10.1016/j.jtcvs.2019.03.028
}

Brain injury associated with congenital heart surgery has been recognized since, well, since the beginning of congenital heart surgery, as described by one of the pioneers of our specialty. ${ }^{1}$ The first few years of open cardiac repairs for congenital heart disease were primarily focused on survival. The past 4 decades have seen a greater focus on neurodevelopmental (ND) outcomes as it became apparent that those children surviving complex operations performed during infancy were not normal from an ND point of view. This was especially true when deep hypothermic circulatory arrest was a part of the operative strategy ${ }^{2}$ and increased with the complexity of the procedure (Figure 1). One difficulty with sorting out cause and effect of the ND outcomes is that these issues may not be readily apparent during the early postoperative course of a small infant and can only be seen once the child is old enough to be formally tested for intelligence quotient or somewhat complex developmental tests. This might be as much as 5 years after the sentinel event. Any evaluation of the impact of changes in the conduct of operations with the technique of the procedure or cardiopulmonary bypass would require a patient investigator to follow these patients for several years before being able to assess the impact of the changes. The Boston Circulatory Arrest study is one of these investigations, and those involved are to be congratulated for this work, which continues to provide ND information about those children undergoing the arterial switch procedure. ${ }^{3}$

The study by Graham and colleagues ${ }^{4}$ evaluated the predictive power of serum levels of glial fibrillary acidic protein (GFAP) as a marker of brain injury. This was then correlated with evidence of abnormalities in ND outcomes when these children reach 1 year of age. ${ }^{4}$ Their study suggests that elevated GFAP levels measured in the perioperative period are predictive of poor ND outcomes as assessed using cognitive, language, and intellectual scores on standardized tests performed at 1 year of age. This would allow an earlier intervention into various developmental therapies that could affect the longer-term outcomes in these patients.

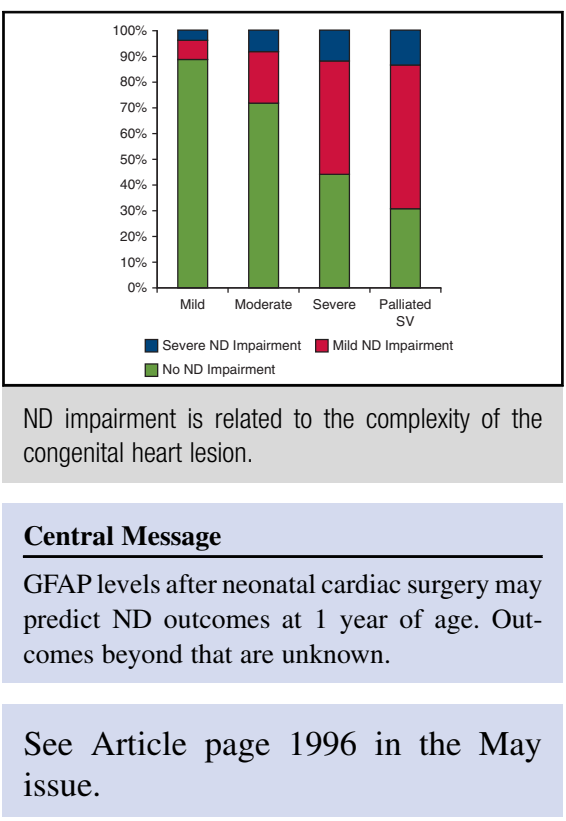

In addition, this finding would aid the study of cardiac surgery and brain injury by shortening the interval between changes in therapy and evaluation of results so that we could create new information in this realm over a shorter duration. The study has flaws that the authors list in the obligatory "Limitations" section of the article. The major flaw in my view was that these patients were part of another randomized study involving the use of steroids in congenital heart surgery. Other additional important limitations include the lack of a specific protocol for the conduct of cardiopulmonary bypass, nonuniform neuroprotective strategies, and the variety of operations performed between both institutions. Those issues are of less concern. I believe that the study should just be viewed as a simple examination of what happens in ND of an infant when postoperative GFAP levels are elevated. Whether their results at 1 year will hold up in the longer term has yet to be determined.

What in the world is GFAP? GFAP is a protein located in neurons and plays a role in cell-cell communication within the central nervous system. It is an important component of maintaining the blood-brain barrier. It was discovered by Amico Bignami and colleagues ${ }^{5}$ (which I think is Italian for friend with big name, ie, famous friend) when researching the plaques found in the central nervous system of patients with multiple sclerosis. The normal serum level is zero, but it is released when there is damage to a neuron, specifically astrocytes, in the central nervous system. It 


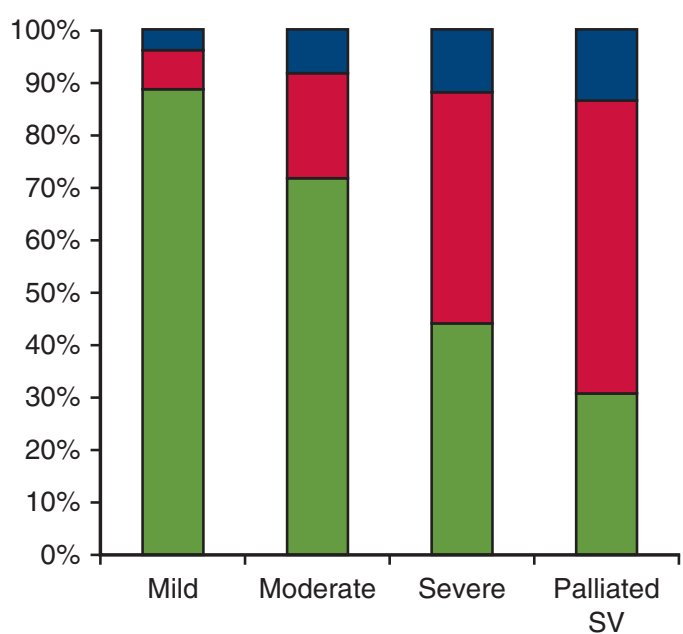

Severe ND Impairment $\square$ Mild ND Impairment

No ND Impairment

FIGURE 1. This relates the degree of neurodevelopmental delay to the complexity of the congenital heart disease. $N D$, Neurodevelopmental; $S V$, single ventricle.

became popular years ago as a potential marker for the severity of traumatic brain injuries, such as concussions. Its use in this area has waned primarily because its correlation with longer-term ( 6 months postinjury) neurologic outcomes has been inconsistent. ${ }^{6}$ It is not a blood test that is available in most medical centers, although there are kits available to run this at approximately $\$ 500$ per sample. Imaging studies of the brain have been the mainstay of neurologic evaluations early in the course of congenital heart disease and surgical treatment thereof. A recent study by
Peyvandi and colleagues ${ }^{7}$ was devoted to the correlation of magnetic resonance imaging findings and long-term ND outcomes. They found that the Bayley Scales of Infant Development scores were not associated with white matter injury on magnetic resonance imaging at 12 months but did at 30 months of age. Why there was a lack of association that did not manifest early on is unclear. There is also appropriate emphasis on the other factors that play a role in ND development, including maternal education, socioeconomic status, and the presence of genetic abnormalities. This must give us pause in how we view the work by Graham and colleagues ${ }^{4}$ on GFAP. Nonetheless, the results of this study are compelling and may offer an additional tool in this area of research.

\section{References}

1. Patrick RT, Kirklin JW, Theye RA. The effects of extracorporeal circulation on the brain. In: Allen JG, ed. Extracorporeal Circulation. Springfield, IL: Charles G. Thomas; 1958:272-8.

2. Wright J, Hicks R, Newman D. Deep hypothermic arrest: observations on later development in children. J Thorac Cardiovasc Surg. 1979;77:466-9.

3. Wypij D, Newburger JW, Rappaport LA, duPlessis AJ, Jonas RA, Wernovsky G, et al. The effect of duration of deep hypothermic circulatory arrest in infant heart surgery on late neurodevelopment: the Boston circulatory arrest trial. J Thorac Cardiovasc Surg. 2003;126:1397-403.

4. Graham EM, Martin RH, Atz AM, Hamlin-Smith K, Kavarana MN, Bradley SM, et al. Association of intraoperative circulating-brain injury biomarker and neurodevelopmental outcomes at 1 year among neonates undergoing cardiac surgery. J Thorac Cardiovasc Surg. 2019;157:1996-2002.

5. Bignami A, Eng LF, Dahl D, Uyeda CT. Localization of the glial fibrillary acidic protein in astrocytes by immunofluorescence. Brain Res. 1972;43:429-35.

6. Lugones M, Parkin G, Bjelosevic S, Takagi M, Clarke C, Anderson V, et al. Blood biomarkers in paediatric mild traumatic brain injury: a systematic review. Neurosci Biobehav Rev. 2018;87:206-17.

7. Peyvandi S, Chau V, Guo T, Xu D, Glass HC, Synnes A, et al. Neonatal brain injury and timing of neurodevelopmental assessment in patients with congenital heart disease. J Am Coll Cardiol. 2018;71:1986-96. 